\title{
Posterior vitreous detachment - prevalence of and risk factors for retinal tears
}

\author{
Martin Bond-Taylor ${ }^{1}$ \\ Gunnar Jakobsson ${ }^{1,2}$ \\ Madeleine Zetterberg ${ }^{1,2}$ \\ 'Department of Ophthalmology, \\ Sahlgrenska University Hospital, \\ Mölndal, ${ }^{2}$ Department of Clinical \\ Neuroscience/Ophthalmology, \\ Institute of Neuroscience and \\ Physiology, Sahlgrenska Academy \\ at University of Gothenburg, \\ Gothenburg, Sweden
}

\author{
This article was published in the following Dove Press journal: \\ Clinical Ophthalmology \\ 18 September 2017 \\ Number of times this article has been viewed
}

Purpose: The present study aimed to describe clinical characteristics of patients with posterior vitreous detachment (PVD), to determine the prevalence of retinal tears in PVD patients, and to find predictors for retinal tears in this patient group.

Methods: Retrospective analysis of medical records on patients diagnosed with PVD, retinal tears, or vitreous hemorrhage at the Department of Ophthalmology at Sahlgrenska University Hospital, a tertiary eye center.

Results: Between February and July 2009, 365 patients consulted the Department of Ophthalmology for PVD-related symptoms. The incidence of retinal tears was $14.5 \%(n=53)$ and that of vitreous and/or retinal hemorrhage was $22.7 \%(n=83)$. For analysis of possible predictors for complications to PVD, patients diagnosed with retinal tears or vitreous hemorrhage between May and July 2009 were also included in the study, resulting in a total of 426 patients. Predictors of a retinal tear were symptoms of visual impairment $(P=0.024)$, the presence of vitreous or retinal hemorrhage at examination $(P<0.001)$, and a duration of symptoms for $<24$ hours $(P=0.004)$. Symptoms of flashes did not constitute an extra risk of retinal tears $(P=0.135$ ). Subsequent retinal pathology (follow-up time 4.5 years), including vitreous detachment/hemorrhage or retinal tears/detachment, occurred more often in patients presenting with a retinal tear. For patients with a retinal tear, the relative risk of having a retinal detachment in the same eye during the follow-up time was 17.7 when compared to patients without a retinal tear (risk ratio $17.7,95 \%$ confidence interval 2.2-145).

Conclusion: Patients seeking care on the first day have a higher risk of retinal tears. Also, symptoms of visual loss or a history of previous PVD-related pathology and vitreous/retinal hemorrhage at examination indicate a substantially higher risk of retinal complications. These findings may lead to better management and order of priority among these patients.

Keywords: posterior vitreous detachment, retinal detachment, retinal hemorrhage, retinal tear

\section{Introduction}

Spontaneous posterior vitreous detachment (PVD) is a common age-related condition in patients aged $\geq 45$ years. The prevalence has been reported to be as high as $24 \%$ among patients aged $50-59$ years and $87 \%$ among patients aged $80-89$ years. ${ }^{1,2}$

Vitreous is composed of collagen fibers $(\sim 0.5 \%)$, hyaluronic acid $(\sim 0.5 \%)$, and water $(\sim 99 \%))^{3}$ It amounts to $\sim 2 / 3$ of the total volume of the eye. The initial gel-like consistency of the vitreous degenerates through a physiological process with age. ${ }^{4}$ At the age of $\leq 50$ years, $25 \%$ of the vitreous exists in water phase, while at 80 years $62 \%$ of the vitreous would have changed from gel phase to water phase. ${ }^{3}$ This physiological change can, in some cases, result in retinal damage through traction with retinal tears/hemorrhages and/or retinal detachment (RD) when collapse occurs. ${ }^{5}$ It should be noted that up to $20 \%$ of PVDs are asymptomatic. ${ }^{6}$ The adherence of the vitreous
Correspondence: Madeleine Zetterberg Department of Ophthalmology, Sahlgrenska University Hospital, SE-43 I 80 Mölndal, Sweden

Tel +46 3I 3433255

Fax +4631412904

Email madeleine.zetterberg@gu.se (c) (1) (-) 2017 Bond-Taylor et al. This work is published and licensed by Dove Medical Press Limited. The full terms of this license are available at https://www.dovepress.com/terms.php (c) ${ }_{\mathrm{BY}} \mathrm{NC}$ and incorporate the Creative Commons Attribution - Non Commercial (unported, v3.0) License (http://creativecommons.org/licenses/by-nc/3.0/). By accessing the work you hereby accept the Terms. Non-commercial uses of the work are permitted without any further permission from Dove Medical Press Limited, provided the work is properly attributed. For permission for commercial use of this work, please see paragraphs 4.2 and 5 of our Terms (https://www.dovepress.com/terms.php). 
is strongest to the retina around the optic nerve head, at the macula, and at the base of the vitreous (at ora serrata). The vitreous is also adherent to the ciliary body and the posterior lens capsule and traction to these structures can cause structural damage. ${ }^{3}$

Patients with PVD often present symptoms in the form of floating clouds and/or lightning in the visual field, that is, floaters and flashes. These floaters are the result of light passing differently through folds created in the shriveling vitreous, aggregated collagen fibers, cells or condensations in the vitreous. This symptomatology may appear months or years after an uncomplicated PVD. ${ }^{4}$ The spots of light or lightning are considered to be caused by the traction on the retina that adhered hard to vitreous conducts. ${ }^{1}$ Several studies have shown that the risk of damage of the retina with the above mentioned symptomatology varies greatly, between $8.2 \%$ and $47.6 \% .^{7-9}$ If no retinal tears or hemorrhages are found at the primary examination of a patient with PVD, further examinations/follow-ups are considered unnecessary, except in the case of new symptoms or worsening of the symptoms. ${ }^{6}$ In the event of a retinal rupture, vitreous fluid can enter the retina through the tear, leading to separation of the neuroretina from the underlying retinal pigment epithelium resulting in RD in $33 \%-46 \%$ of the cases. ${ }^{1}$ If the separated neuroretina and its photoreceptors are left without surgical intervention, the photoreceptors will inevitably undergo apoptosis. ${ }^{10}$

The objective of the present study was to evaluate what clinical symptoms (floaters, flashes, visual decrease) may predict complications such as RD, tear and/or hemorrhage after a PVD, both with respect to short term and after a follow-up of several years. Another aim was to determine how the duration of symptoms prior to first consulting an ophthalmologist correlates with the risk of these complications. Better knowledge of these clinical characteristics will lead to optimized management of PVD patients.

\section{Materials and methods}

\section{Participants and inclusion criteria}

All patients $(n=365)$ presenting at the Department of Ophthalmology at Sahlgrenska University Hospital with symptoms of PVD were retrospectively included during a 3-month period (February-April 2009) if they had obtained the International Classification of Diseases No 10 (ICD-10) diagnosis codes for retinal tear $(\mathrm{H} 33.3, \mathrm{H} 33.3 \mathrm{~A}, \mathrm{H} 33.3 \mathrm{~B}$, H33.3W, H33.3X), vitreous hemorrhage (H43.1), or vitreous detachment (H43.8, H43.8A, H43.8B). Obtaining one or more of these diagnosis codes was sufficient for diagnosis; hence, a Weiss ring was not required for diagnosis of vitreous detachment; symptoms of floaters were enough. The prevalence of complications such as retinal tears among those who consulted an ophthalmologist for PVD-related symptoms was based on the patients recruited during this time period. In order to obtain a sufficient number of cases for a casecontrol study on possible risk factors for retinal complications in PVD patients, an additional 61 patients diagnosed with retinal ruptures $(n=53)$ and/or vitreous hemorrhage $(n=8)$ during the period of May-July 2009 were also included, yielding a total number of 426 patients. For the latter period, patients received the ICD-10 diagnosis codes for retinal tears (H33.3, H33.3A, H33.3B, H33.3W, H33.3X) and/or vitreous hemorrhage (H43.1). This case-control part of the study thus consisted of patients seeking care for PVD-related symptoms, where the cases were patients in whom retinal tears were detected and controls were patients with similar symptoms who did not exhibit retinal tears.

The study adhered to the tenets of the Declaration of Helsinki and was approved by the local Ethical Committee of the University of Gothenburg. According to the ethical committee, consent from the patient is not necessary in this type of retrospective study. In order to ensure confidentiality, all patient data were coded prior to statistical analysis.

Medical records of the included patients were reviewed for symptoms (floaters, flashes, and visual decrease), duration of symptoms prior to consulting an ophthalmologist, previous PVD-related symptoms, objective findings at ocular examination, and possible future symptomatology concerning PVD or associated complications. Follow-up time was 4.5 years and data on previous PVD-related pathology could be retrieved since 2002 from the Digital Medical Journal System (Melior, Sahlgrenska University Hospital).

\section{Statistical analysis}

Mean and standard deviation (SD) and/or median with interquartile range (IQR) are given as appropriate. For statistical analysis, Student's $t$-test and Mann-Whitney $U$ test for two independent samples were used. For categorical data, chi-square test for small samples (Fisher's exact test) was used. A $P$-value $<0.05$ was considered statistically significant. As statistical software, SPSS, version 22.0 for Mac (IBM Corporation, Armonk, NY, USA) was used.

\section{Results}

The demographics of the patients included in this study are presented in Table 1. A cohort of 365 patients presenting at the Department of Ophthalmology at Sahlgrenska University 
Table I Demographics of all patients diagnosed with vitreous detachment, retinal tears, or vitreous hemorrhage at the Sahlgrenska University Hospital during a 3-month period in 2009

\begin{tabular}{ll}
\hline Parameter, $\mathbf{n = 3 6 5}$ & Years or $\mathbf{n}(\%)$ \\
\hline Age, years & \\
$\quad$ Mean (SD) & $62.8(10.6)$ \\
$\quad$ Median (range) & $63.0(\mathrm{I} 2-94)$ \\
Sex, $\mathrm{n}(\%)$ & \\
$\quad$ Female & $228(62.5 \%)$ \\
$\quad$ Male & $137(37.5 \%)$ \\
Diagnosis code (ICD-I0), $\mathrm{n}(\%)$ & \\
$\quad$ Vitreous detachment (H43.8) & $300(82.2 \%)$ \\
Retinal tear (H33.3) & $48(13.2 \%)$ \\
$\quad$ Vitreous hemorrhage (H43.I) & $17(4.6 \%)$ \\
Objective findings, $\mathrm{n}(\%)$ & \\
$\quad$ Retinal tear & $53(14.5 \%)$ \\
$\quad$ Hemorrhage & $83(22.7 \%)$ \\
Checkup consultations performed, $\mathrm{n}(\%)$ & $75(20.6 \%)$ \\
\hline
\end{tabular}

Notes: *In the medical journal, each patient was given only one main diagnosis, which was used to classify the patients in the study. "Including retinal and vitreal hemorrhages but excluding hemorrhages related to diabetic retinopathy.

Abbreviations: ICD-10, International Classification of Diseases No 10; SD, standard deviation.

Hospital during the period of February-April 2009 was reviewed. Mean age was 62.8 years $( \pm 10.2 \mathrm{SD})$ and there was a higher proportion of women $(62.5 \%)$ than men $(37.5 \%)$. The most frequent diagnosis code was PVD (H43.8-, A, B; $82.2 \%$ ), followed by retinal tear (H33.3-, A, B, W, X; 13.2\%), and vitreous hemorrhage (H43.1; 4.6\%). Patients obtained only one main diagnosis, by which they were classified. However, many patients had several diagnoses, like patients with retinal tears who also most likely had a vitreous detachment. In addition, only a small number of patients received vitreous hemorrhage as the main diagnosis, presumable because the majority of these patients only had a small amount of erythrocytes in the vitreous (which was described in the medical record among the signs) but instead they were classified as vitreous detachment or retinal tears. The eye examination showed an incidence of retinal tears of $14.5 \%$ and hemorrhage of $22.7 \%$, using both patients who were coded as retinal tears, vitreous hemorrhage, or vitreous detachment as denominator. Follow-up visits were performed in $20.6 \%$ of the cases.

When comparing PVD patients without $(n=320)$ or with $(n=106)$ retinal tears (Table 2$)$, there was no significant difference in age, laterality, or symptomatology with regard to floaters and flashes. The mean age of patients with uncomplicated PVD versus those with retinal tears was $63.7( \pm 10.8 \mathrm{SD})$ and $62.6( \pm 10.3 \mathrm{SD})$ years, respectively; the IQR was similar for both groups, with the majority of patients being between 59 and 70 years of age. Floaters were present in $>90 \%$ of the patients within both groups whereas about half of the patients had experienced flashes, $P=0.499$ and $P=0.135$, respectively. On the other hand, subjective visual decrease was significantly more frequent among patients with retinal tears $(20.4 \%)$ than in those without a retinal tear $(10.9 \%, P=0.024)$. Women were in majority in both groups, but the proportion of men was increased in those presenting with retinal tears, a borderline significant difference $(P=0.051)$.

A vast majority of all patients $(76.0 \%)$ seeking care at Sahlgrenska University Hospital for PVD-related symptoms did so within the first 7 days (Figure 1). A total of $83 \%$ of all confirmed retinal tears in our data were found within 7 days from the onset of symptoms. For patients with PVD symptoms without tears, the corresponding number was $73.7 \%$ ( $P=0.065)$. Patients who sought care with a symptom duration of PVD for $\leq 24$ hours had a significantly higher risk of having a retinal tear $(P=0.004$; Table 2$)$.

No significant differences were evident regarding objective findings (floaters, Weiss ring) or previous cataract surgery with regard to the risk of having a retinal tear (Table 2). Within the follow-up time of 4.5 years for this study, there was a highly significant difference in the risk of future retinal pathology between groups, both for same eye and the other eye $(P<0.001$ and $P=0.001)$. In the retinal tear group, $16.5 \%$ of the patients developed new PVD symptoms in the same eye, $3.9 \%$ experienced a new retinal tear, and $5.8 \%$ had a RD compared to $5.6 \%, 1.3 \%$, and $0.3 \%$, respectively, in the group with no retinal tear at the initial visit. Patients presenting with a retinal tear at the initial examination were 17.7 times more likely to experience a $\mathrm{RD}$ in the same eye during the follow-up period of 4.5 years than patients with PVD symptoms without a retinal tear (risk ratio $=17.7,95 \%$ confidence interval $2.2-145$ ).

\section{Discussion}

The present study showed an incidence of retinal tears of $14.5 \%$ and hemorrhages of $22.7 \%$ in patients with symptoms of PVD. This relates well to the incidence in previous studies. ${ }^{8,9}$

The most striking finding with relevance for clinical practice is that patients who seek care within the first day of symptoms have a significantly higher incidence of retinal tears compared to people who wait to seek care the following days or at a later time. In our opinion, this may reflect more pronounced symptoms in PVD associated with retinal tears, something that could make the patients prone to seek care more urgently. The impact of the duration of symptoms 
Table 2 Clinical characteristics in patients with vitreous detachment-related symptoms and possible predictors for retinal tears

\begin{tabular}{|c|c|c|c|}
\hline Parameters $(n=426) *$ & $\begin{array}{l}\text { No retinal tear } \\
(n=320)\end{array}$ & $\begin{array}{l}\text { Retinal tear } \\
(n=106)\end{array}$ & $P$-value** \\
\hline \multicolumn{4}{|l|}{ Age, years } \\
\hline Mean (SD) & $63.7(10.8)$ & $62.6(10.3)$ & $0.37^{\ddagger}$ \\
\hline Median (IQR) & $64.5(59-70)$ & $63(59-68)$ & \\
\hline \multicolumn{4}{|l|}{ Sex, n (\%) } \\
\hline Female & $204(63.7 \%)$ & $56(52.8 \%)$ & $0.05^{\S}$ \\
\hline Male & $116(36.3 \%)$ & $50(47.2 \%)$ & \\
\hline \multicolumn{4}{|l|}{ Eye, n (\%) } \\
\hline Right & |7| (53.4) & $50(47.2)$ & $0.31^{\S}$ \\
\hline Left & $149(46.6)$ & $56(52.8)$ & \\
\hline \multicolumn{4}{|l|}{ Symptoms* } \\
\hline Floaters, $n=316, n=102$ & $293(92.7 \%)$ & 97 (95.1\%) & $0.50^{\S}$ \\
\hline Flashes, $n=3|3, n=| 0 \mid$ & 177 (56.5\%) & 48 (47.5\%) & $0.14 \S$ \\
\hline Visual impairment, $n=258, n=98$ & $28(10.9 \%)$ & $20(20.4 \%)$ & $0.02^{\S}$ \\
\hline \multicolumn{4}{|l|}{ Duration of symptoms, $\mathrm{n}(\%)^{*}$} \\
\hline$\leq 1$ day, $\mathrm{n}=315, \mathrm{n}=106$ & $80(25.4 \%)$ & $43(40.6 \%)$ & $0.004 \S$ \\
\hline$\leq 7$ days, $\mathrm{n}=315, \mathrm{n}=106$ & $232(73.7 \%)$ & $88(83.0 \%)$ & $0.07^{\S}$ \\
\hline \multicolumn{4}{|l|}{ Objective findings, $\mathrm{n}(\%)^{*}$} \\
\hline Vitreous opacities, n=282, n=86 & $274(97.2 \%)$ & $84(97.7 \%)$ & $1.00 \S$ \\
\hline Weiss ring, $n=112, n=19$ & I0I (90.2\%) & 17 (89.5\%) & $1.00 \S$ \\
\hline Retinal tear & $0(0 \%)$ & $106(100 \%)$ & NA \\
\hline Hemorrhage, ${ }^{\pi} n=320, n=102$ & $54(16.9 \%)$ & $72(70.6 \%)$ & $<0.00 I^{\S}$ \\
\hline Pseudophakic, $n=196, n=45$ & 39 (19.9\%) & $4(8.9 \%)$ & $0.09 \S$ \\
\hline \multicolumn{4}{|l|}{ Medical history, $\mathrm{n}(\%)^{*, \#}$} \\
\hline Previous symptoms in same eye, $n=290, n=102$ & $50(17.2 \%)$ & $13(12.7 \%)$ & $0.35^{\S}$ \\
\hline Previously sought care in same eye, $n=292, n=102$ & $4 \mathrm{I}(\mathrm{I} 4.0 \%)$ & $13(12.7 \%)$ & $0.87^{\S}$ \\
\hline Previous laser therapy in same eye, $n=293, n=102$ & $21(7.2 \%)$ & $6(5.9 \%)$ & $0.82^{\S}$ \\
\hline Previous symptoms in other eye, $n=291, n=102$ & 47 (16.2\%) & $12(11.8 \%)$ & $0.34 \S$ \\
\hline \multicolumn{4}{|l|}{ Future pathology, $\mathrm{n}(\%)^{*\|\|}$} \\
\hline \multicolumn{4}{|l|}{ Same eye, $n=304, n=103$} \\
\hline Vitreoretinal complications ${ }^{t}$ & $26(8.6 \%)$ & $29(28.2 \%)$ & $<0.00 I^{\S}$ \\
\hline Vitreous detachment & $17(5.6 \%)$ & $17(16.5 \%)$ & $0.001^{\S}$ \\
\hline Vitreous hemorrhage & $4(1.3 \%)$ & $2(1.9 \%)$ & $0.65^{\S}$ \\
\hline Retinal tear & $4(1.3 \%)$ & $4(3.9 \%)$ & $0.12^{\S}$ \\
\hline Retinal detachment & $\mathrm{I}(0.3 \%)$ & $6(5.8 \%)$ & $0.001^{\S}$ \\
\hline \multicolumn{4}{|l|}{ Other eye, $n=304, n=102$} \\
\hline Vitreoretinal complications ${ }^{t}$ & 39 (I2.8\%) & 30 (29.1\%) & $0.00 I^{\S}$ \\
\hline Vitreous detachment & $30(9.9 \%)$ & $21(20.6 \%)$ & $0.0 I^{\S}$ \\
\hline Vitreous hemorrhage & $3(1.0 \%)$ & $0(0.0 \%)$ & $0.58^{\S}$ \\
\hline Retinal tear & $4(1.3 \%)$ & $6(5.9 \%)$ & $0.02^{\S}$ \\
\hline Retinal detachment & $2(0.7 \%)$ & $2(2.0 \%)$ & $0.26^{\S}$ \\
\hline
\end{tabular}

Notes: *Including all patients diagnosed with vitreous detachment/hemorrhage or retinal tears in February-April 2009 ( $n=365$ ) and all patients diagnosed with retinal tears or hemorrhage in May-July 2009 ( $\mathrm{n}=6 \mathrm{I}$ ). When data are missing, specific $\mathrm{n}$ is given for that variable. **A $P$-value $<0.05$ was considered statistically significant. $¥$ Student's $t$-test. 'Fisher's exact test. "Including retinal and vitreal hemorrhages, but excluding hemorrhages related to diabetic retinopathy. ${ }^{\# R e f e r s ~ t o ~ p r e v i o u s ~ s y m p t o m s, ~ s o u g h t ~}$ care, or laser treatment related to vitreous detachment or hemorrhage, retinal tears, or rhegmatogenous retinal detachment within the last 7 years. "Includes vitreous detachment or hemorrhage, retinal tears, or rhegmatogenous retinal detachment with a follow-up time of 4.5 years. ${ }^{ \pm}$Including vitreous detachment/hemorrhage and retinal tears/detachment.

Abbreviations: IQR, interquartile range; NA, not applicable; SD, standard deviation.

has previously been discussed by Dayan et al who showed that $<6$ weeks of symptoms is associated with a higher risk of retinal tears. ${ }^{9}$ However, this is to our knowledge the first study to show a pronounced difference in the proportion of patients consulting an ophthalmologist after one day of PVD symptoms; $41 \%$ versus $25 \%$ of patients with/without retinal tears, respectively.
In the present study, visual impairment was found to be a predictor for retinal pathology, which is in accordance with previous studies where $67 \%$ of patients with decreased visual acuity had retinal tears or detachments whereas $19 \%$ of patients with floaters or flashes alone had these conditions. ${ }^{9}$ Other studies have shown a correlation between the number of floaters and the risk of retinal tears..$^{5,11,12}$ 


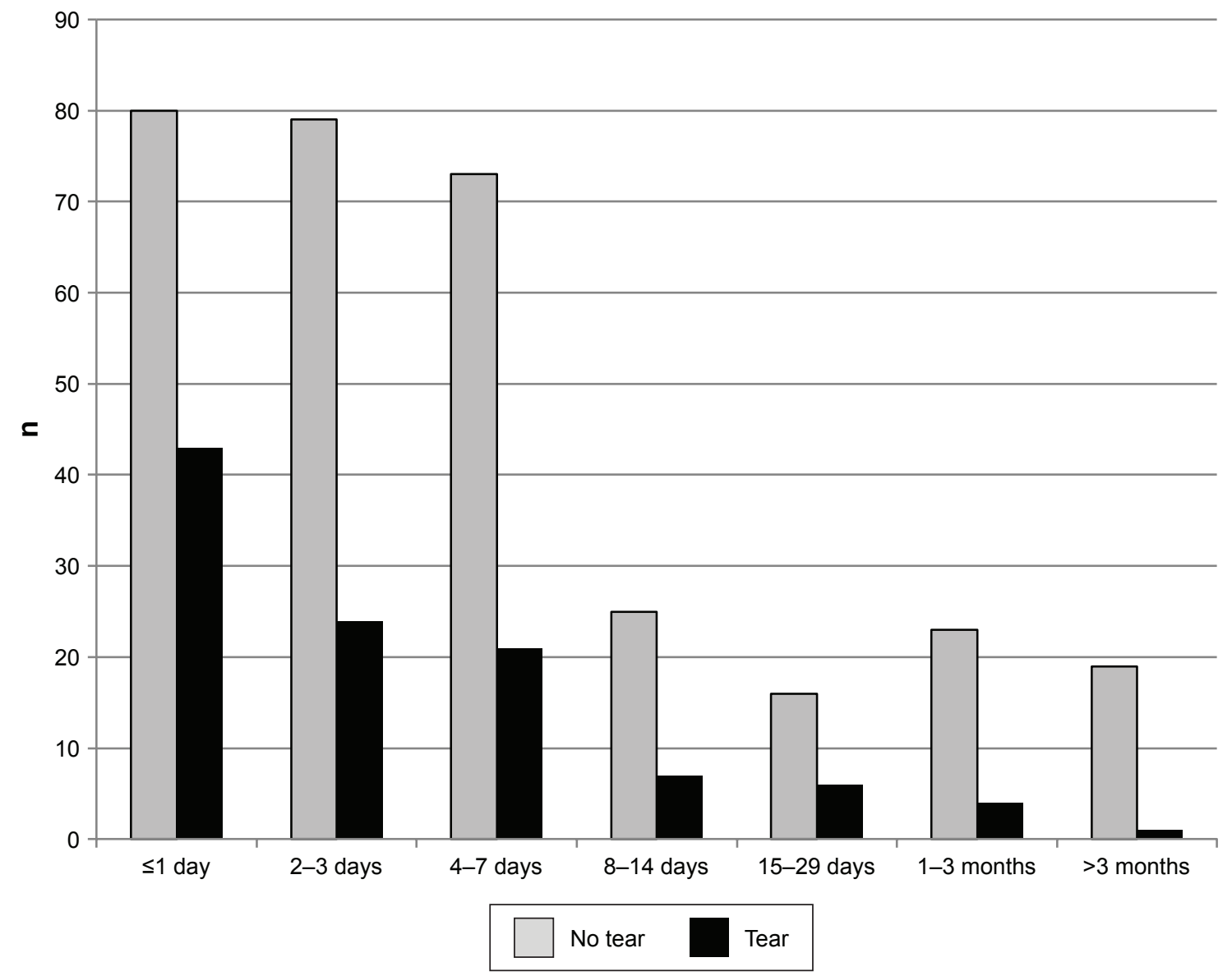

Figure I Duration of symptoms of vitreous detachment for patients with and without retinal tears prior to consulting an ophthalmologist. Notes: Duration of symptoms of vitreous detachment is given in days including 315 patients without and 106 patients with retinal tears. All subjects were examined at the Department of Ophthalmology at Sahlgrenska University Hospital between February and July 2009.

In a study by Byer, $29 \%$ of patients with secondary retinal tears on initial examination had one to two floaters and light flashes as the only symptoms. ${ }^{13}$ Thus, Byer regarded PVD symptoms as being potentially serious and stated that a rapid vitreoretinal examination should be conducted to avoid rhegmatogenous RD.

As previously shown, the incidence of RD is higher among men (13.09 vs 7.41 per 100,000). ${ }^{14}$ This is in line with our results showing a borderline significant overweight of men in the group with tears compared to the group with uncomplicated PVD. However, in the present study, women were in majority in both groups, indicating that there may be other factors determining the risk of RD than purely PVD. The results may also be interpreted as women being more prone to seek care for PVD-related symptoms, thereby avoiding a subsequent RD.

Floaters were the most prominent symptom, present in $>90 \%$ of the patients and this correlated well with the proportion exhibiting vitreous opacities during ophthalmological examination (97\%). In most cases $(<90 \%)$, there was a visible Weiss ring, confirming that posterior detachment of the vitreous had occurred.

A previous study showed floaters in $42 \%$, flashes in $18 \%$, and both floaters and flashes in $20 \%$ of patients with PVD and secondary retinal pathology. ${ }^{9}$ The incidence of retinal rupture increased from $4 \%-5 \%$ with only floaters to $10 \%-11 \%$ with flashes with/without floaters in a study performed by Richardson et al. ${ }^{6}$ However, floaters alone should not be discarded as unimportant; Dayan et al states that $26.7 \%$ of the retinal tears or RD occurred with floaters alone. ${ }^{9}$

The risk of retinal tears has been shown to be higher if the patient presents with vitreous or retinal hemorrhage at the initial consultation. ${ }^{8}$ The risk of a retinal tear then increases from $4 \%-5 \%$ to $30 \%-90 \%$ according to Sarrafizadeh et al. ${ }^{15}$ In the present study, the presence of hemorrhage was significantly higher in patients with retinal tear $(70.6 \%)$ than no retinal tear $(16.9 \%)$. This was also found, but to a lesser extent, in a previous study. ${ }^{16}$

Byer presented a $13.1 \%$ rate of retinal tears in phakic eyes and $36.8 \%$ in aphakic. ${ }^{13}$ Further, a rate of RD at initial 
examination of $2.4 \%$ ( 8 of 329 ) in phakic eyes and $28.5 \%$ (6 of 21) in aphakic patients has been reported. Previous cataract surgery is a well-known risk factor for RD with a cumulative probability of developing RD 5.5 times more than for those not having cataract surgery. ${ }^{17,18}$ In this study, however, there was no significant difference in the proportion of retinal tear between phakic and pseudophakic patients.

Our data showed that having a retinal tear is a risk factor for the development of future vitreoretinal pathologies, regardless of the eye in question. Approximately $28 \%$ of the patients diagnosed with retinal tears had new PVD symptoms, retinal tears, hemorrhages, or RDs within the next 4.5 years. $\mathrm{RD}$ was seen in $5.8 \%$ of the patients with retinal tear over a 4.5-year period, corresponding to a relative risk of 17.7 when compared to patients with PVD symptoms who did not have a retinal tear at the initial examination. Patients presenting with a retinal tear, especially if associated with new PVDrelated symptoms, were treated with laser as prophylaxis against $\mathrm{RD}$; the increased risk of retinal complications was thus despite this preventive measure.

It has been shown that PVD usually occurs in the other eye within 6 months to 2 years after the first eye. ${ }^{19}$ It is likely that PVD is a parallel process in both eyes and thus the patient should be informed of possible pathologies not only in the eye with the present pathology but also in the other eye as well. Hence, the presence of a retinal tear should promote special attention to the retinal status of such a patient in the future. Further information and possible rapid response might be prudent regarding these patients who have presented with previous retinal damage.

Ideally, the diagnosis of PVD should be made using ultrasound or optical coherence tomography and preferably ophthalmoscopy should demonstrate a Weiss ring. However, given the retrospective nature of the study, this was not possible. Instead, this study used diagnosis codes as the definition of disease, which is a limitation of the study. The retrospective design also resulted in scarce data on, for instance, lens status. The small sample size available for analysis of the effect of pseudophakia may explain why we did not detect an effect of previous cataract surgery on the risk of retinal tear. Also, the retrospective design made it difficult to classify hemorrhages as either retinal or vitreal, although it is likely that the latter was derived from the former. Another limitation of the study is that we did not have access to medical journals from private or other public ophthalmic clinics in the area; hence, we do not know by certainty whether patients previously diagnosed with PVD in our clinic were later diagnosed with retinal tears or hemorrhages elsewhere, something that may have resulted in underestimation of the number of subsequent complications. However, since Sahlgrenska University Hospital was the only ophthalmic unit performing vitreoretinal surgery in the western part of Sweden during the period, it may be assumed that all cases with RD were included in the study.

\section{Conclusion}

Special regard and prompt attention to patients who present with visual impairment and seek care within 24 hours of symptom onset should be given, whereas patients with only floaters and long duration of symptoms may be regarded as low risk patients of retinal tears. In this study, 95.3\% (101 of 106) of confirmed retinal ruptures were diagnosed within the first month. The remainder were spread out during the following 2 months, with only one case found at a later date. Hence, it can be stated that a duration of symptoms longer than 1 month results in very few confirmed retinal tears, something that may provide a time frame for retinal examination after PVD symptoms. Furthermore, it is advisable to pay special attention to patients with previous retinal tears since this group presents a higher risk of future retinal pathology.

\section{Acknowledgments}

This work was supported by grants from the Sahlgrenska University Hospital ("Agreement concerning research and education of doctors"; ALFGBG-441721), Göteborg Medical Society, Dr Reinhard Marcuses Foundation, Konung Gustaf V:s och Drottning Victorias Frimurarestiftelse, Hjalmar Svensson Foundation, Greta Andersson Foundation, Herman Svensson Foundation, Ögonfonden, De Blindas Vänner, and Kronprinsessan Margaretas Arbetsnämnd för Synskadade.

\section{Disclosure}

The authors report no conflicts of interest in this work.

\section{References}

1. Hollands H, Johnson D, Brox AC, Almeida D, Simel DL, Sharma S. Acute-onset floaters and flashes: is this patient at risk for retinal detachment? JAMA. 2009;302(20):2243-2249.

2. Rahman R, Ikram K, Rosen PH, Cortina-Borja M, Taylor ME. Do climatic variables influence the development of posterior vitreous detachment? Br J Ophthalmol. 2002;86(7):829.

3. Thimons JJ. Posterior vitreous detachment. Optom Clin. 1992;2(3): $1-24$.

4. Johnson MW. Posterior vitreous detachment: evolution and complications of its early stages. Am J Ophthalmol. 2010;149(3):371-382.

5. Schweitzer KD, Eneh AA, Hurst J, Bona MD, Rahim KJ, Sharma S. Predicting retinal tears in posterior vitreous detachment. Can J Ophthalmol. 2011;46(6):481-485. 
6. Richardson PS, Benson MT, Kirkby GR. The posterior vitreous detachment clinic: do new retinal breaks develop in the six weeks following an isolated symptomatic posterior vitreous detachment? Eye (Lond). 1999;13(Pt 2):237-240.

7. Brod RD, Lightman DA, Packer AJ, Saras HP. Correlation between vitreous pigment granules and retinal breaks in eyes with acute posterior vitreous detachment. Ophthalmology. 1991;98(9):1366-1369.

8. Coffee RE, Westfall AC, Davis GH, Mieler WF, Holz ER. Symptomatic posterior vitreous detachment and the incidence of delayed retinal breaks: case series and meta-analysis. Am J Ophthalmol. 2007; 144(3):409-413.

9. Dayan MR, Jayamanne DG, Andrews RM, Griffiths PG. Flashes and floaters as predictors of vitreoretinal pathology: is follow-up necessary for posterior vitreous detachment? Eye (Lond). 1996;10(Pt 4): 456-458.

10. Chang CJ, Lai WW, Edward DP, Tso MO. Apoptotic photoreceptor cell death after traumatic retinal detachment in humans. Arch Ophthalmol. 1995;113(7):880-886.

11. van Overdam KA, Bettink-Remeijer MW, Mulder PG, van Meurs JC. Symptoms predictive for the later development of retinal breaks. Arch Ophthalmol. 2001;119(10):1483-1486.

12. van Overdam KA, Bettink-Remeijer MW, Klaver CC, Mulder PG, Moll AC, van Meurs JC. Symptoms and findings predictive for the development of new retinal breaks. Arch Ophthalmol. 2005;123(4): 479-484.
13. Byer NE. Natural history of posterior vitreous detachment with early management as the premier line of defense against retinal detachment. Ophthalmology. 1994;101(9):1503-1513.

14. Mitry D, Tuft S, McLeod D, Charteris DG. Laterality and gender imbalances in retinal detachment. Graefes Arch Clin Exp Ophthalmol. 2011;249(7):1109-1110.

15. Sarrafizadeh R, Hassan TS, Ruby AJ, et al. Incidence of retinal detachment and visual outcome in eyes presenting with posterior vitreous separation and dense fundus-obscuring vitreous hemorrhage. Ophthalmology. 2001;108(12):2273-2278.

16. Sharma S, Walker R, Brown GC, Cruess AF. The importance of qualitative vitreous examination in patients with acute posterior vitreous detachment. Arch Ophthalmol. 1999;117(3):343-346.

17. Desai P. Cataract surgery and retinal detachment: cause and effect? Br J Ophthalmol. 1996;80(8):683-684.

18. Rowe JA, Erie JC, Baratz KH, et al. Retinal detachment in Olmsted County, Minnesota, 1976 through 1995. Ophthalmology. 1999;106(1): $154-159$.

19. Hikichi T. Time course of posterior vitreous detachment in the second eye. Curr Opin Ophthalmol. 2007;18(3):224-227.
Clinical Ophthalmology

\section{Publish your work in this journal}

Clinical Ophthalmology is an international, peer-reviewed journal covering all subspecialties within ophthalmology. Key topics include: Optometry; Visual science; Pharmacology and drug therapy in eye diseases; Basic Sciences; Primary and Secondary eye care; Patien Safety and Quality of Care Improvements. This journal is indexed on

Submit your manuscript here: http://www.dovepress.com/clinical-ophthalmology-journal

\section{Dovepress}

PubMed Central and CAS, and is the official journal of The Society of Clinical Ophthalmology (SCO). The manuscript management system is completely online and includes a very quick and fair peer-review system, which is all easy to use. Visit http://www.dovepress.com/ testimonials.php to read real quotes from published authors. 